\title{
Finite Element Analysis of Buckling of Corrugated Fiberboard
}

\author{
Yali Ma ${ }^{*}$, Zhen Gong $^{1}$, Liang Zhao ${ }^{1}$, Yue Han $^{1}$ and Yun Wang ${ }^{2}$ \\ ${ }^{I}$ School of Mechanical Engineering, Dalian University of Technology, Dalian, 116024, P.R. China; \\ ${ }^{2}$ School of Naval Architecture and Ocean Engineering, Dalian University of Technology, Dalian, 116024, P.R. China
}

\begin{abstract}
This paper investigates the relationship between mechanical behaviors and the shape of corrugated fiberboard by means of buckling analysis, which is done by FEM (Finite Element Method). Firstly, after analyzing the structure of corrugated fiberboard, a single-wall corrugated fiberboard model was built. The buckling load was measured in the ideal condition by linear buckling analysis (eigenvalue buckling analysis). Subsequently, nonlinear buckling analysis based on single-wall corrugated fiberboard was performed using the results of the eigenvalue buckling analysis. Finally, a finite element 3-D model of four-layer and five-layer corrugated fiberboard was established using ANSYS parametric design language (APDL) to improve mechanical properties of corrugated fiberboard based on comparing different eigenvalue buckling loads.
\end{abstract}

Keywords: Corrugated fiberboard, FEM, Eigenvalue buckling, nonlinear buckling.

\section{INTRODUCTION}

Corrugated paper is characterized by regular and permanent ripples. Corrugated fiberboard, widely used in the packaging industry owing to its lightness, resistance to shock and low cost, is a sandwich plate composed of cores and facing plates agglutinated between paper strips or paperboard. Corrugated fiberboard also offers favorable adaptability to be used in decoration and printing and is commonly recycled.

A large amount of research has been done to find ways of improving the performance of corrugated fiberboard. A Nonlinear Finite Element Method was developed to calculate the edge crush strength and bending stiffness for different flute profiles [1]. In order to make a comparison between material failure and structural failure, Nyman [2] presented a failure stress criterion for corrugated board facing. Lu et al. [3] replicated the experimental research on local crushing, to determine overall deformation under the condition of the initial sinusoidal core of corrugated board with vertical load. M. E. Biancolini and Brutti [4] studied the bucking behavior of corrugated paper packages. Buannic et al. [5] focused on the computation of effective properties of corrugated core sandwich panels with the accuracy of the homogenization method. Rami Haj-Ali [6] proposed a refined modeling approach that yielded good predictions for the overall mechanical behavior of wide range of corrugated systems. Chun H. Wan et al. [7] explored novel designs of lightweight load-bearing structures in transportation vehicles which were capable of energy absorption.

In this paper, mechanical properties of corrugated fiberboard were analyzed based on the results of buckling

*Address correspondence to this author at the Linggong Road, Dalian, Liaoning, China. Postcard: 116024, P.R. China; Tel: +86 0411-84708081502; E-mail: myl@dlut.edu.cn analysis, showing the efficiency and accuracy of the model of single-wall corrugated fiberboard. Nonlinear buckling analysis of single-wall corrugated fiberboard was carried out using the results of eigenvalue buckling analysis, and by analyzing the bucking load with the consideration of imperfection condition. In order to discuss the mechanical properties with different heights and wavelengths of corrugated core, different shapes and sizes were built. Based on the comparison of five and four flat faces of corrugated fiberboard, the corresponding behaviors can be analyzed.

\section{THE BUCKLING AND ANALYSIS MODEL OF CORRUGATED FIBERBOARD}

With respect to an ideal elastic structure, eigenvalue buckling analysis is applicable because it is based on Small Deformation Theory and ignores the deformation of structure during the uploading process. However, the results cannot be applied in actual engineering conditions. Therefore, nonlinear buckling analysis, which mainly analyzes the stress deformation variation of structure during the uploading process based on the Theory of Large Deformation, may achieve better results in actual engineering conditions.

Buckling analysis of corrugated fiberboard by FEM requires confirming the material constants, selecting proper units, establishing per unit constants, building geometric models and dividing mesh.

The FEM model of corrugated fiberboard. Corrugated fiberboard is composed of a corrugated core and two facing plates (shown in Fig. 1a) called single-wall corrugated fiberboard. When corrugated fiberboard has a two layered structure connected by an adhesive joint, it is called doublewall corrugated fiberboard (shown in Fig. 1b). The singlewall corrugated fiberboard is the object of study in this paper. 


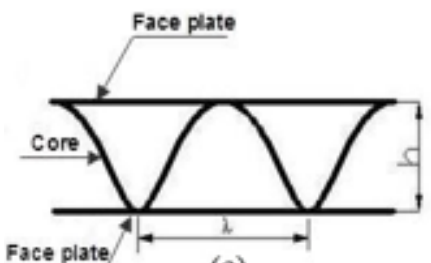

(a)

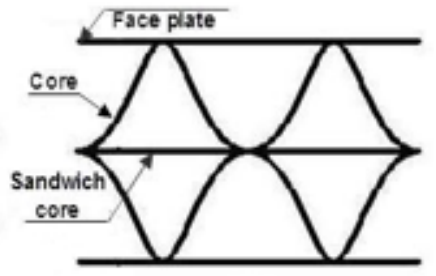

(b)
Fig. (1). Single-wall and Double-wall corrugated fiberboards.

The geometric model of single-wall corrugated fiberboard can be employed by cementing the three surfaces together. Following this, the real constant of shell unit can be built based on the thickness of corrugated fiberboard's each surface as shown in Table 1.

Table 1. Material constants and thickness of corrugated fiberboard.

\begin{tabular}{|c|c|c|c|}
\hline & $\begin{array}{c}\text { Surface } \\
\text { Layer }\end{array}$ & $\begin{array}{c}\text { Corrugated } \\
\text { Core }\end{array}$ & $\begin{array}{c}\text { Surface } \\
\text { Layer }\end{array}$ \\
\hline \hline $\mathrm{E}_{\mathrm{x}}(\mathrm{Mpa})$ & 7600 & 5400 & 6660 \\
\hline $\mathrm{E}_{\mathrm{y}}(\mathrm{Mpa})$ & 4020 & 2280 & 3310 \\
\hline $\mathrm{E}_{\mathrm{z}}(\mathrm{Mpa})$ & 38 & 27 & 33 \\
\hline $\mathrm{V}_{\mathrm{xy}}$ & 0.34 & 0.34 & 0.34 \\
\hline $\mathrm{V}_{\mathrm{xz}}$ & 0.01 & 0.01 & 0.01 \\
\hline $\mathrm{V}_{\mathrm{yz}}$ & 0.01 & 0.01 & 0.01 \\
\hline $\mathrm{G}_{\mathrm{xy}}(\mathrm{Mpa})$ & 2140 & 1360 & 1820 \\
\hline $\mathrm{G}_{\mathrm{xz}}(\mathrm{Mpa})$ & 138 & 98 & 121 \\
\hline $\mathrm{G}_{\mathrm{yz}}(\mathrm{Mpa})$ & 115 & 65 & 95 \\
\hline $\mathrm{Thickness}_{\mathrm{m}}$ & 0.269 & 0.263 & 0.264 \\
\hline
\end{tabular}

Two surface layers and a corrugated core comprise of a single-wall corrugated fiberboard, (shown in Fig. 1) whose major parameters include height $h$ and wavelength $\lambda$. Taking into account the shape of the core layer making influence on the compression strength, the shape of the core layer was observed as sinusoid, which is approximately simplified as straight lines in the FEM model used in this paper. Furthermore, the cementation quality between the surface layers and the core layer was assumed to be good, and, the cement structure was simplified as two layers and core layer with common nodes as shown in Fig. (2).

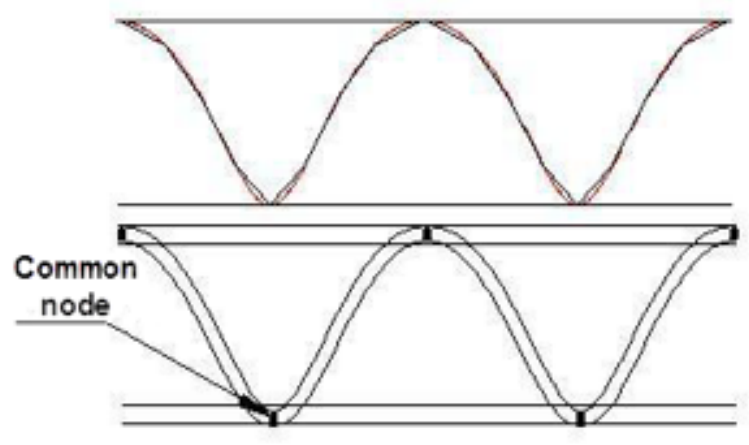

Fig. (2). Simplifying model of corrugated fiberboard

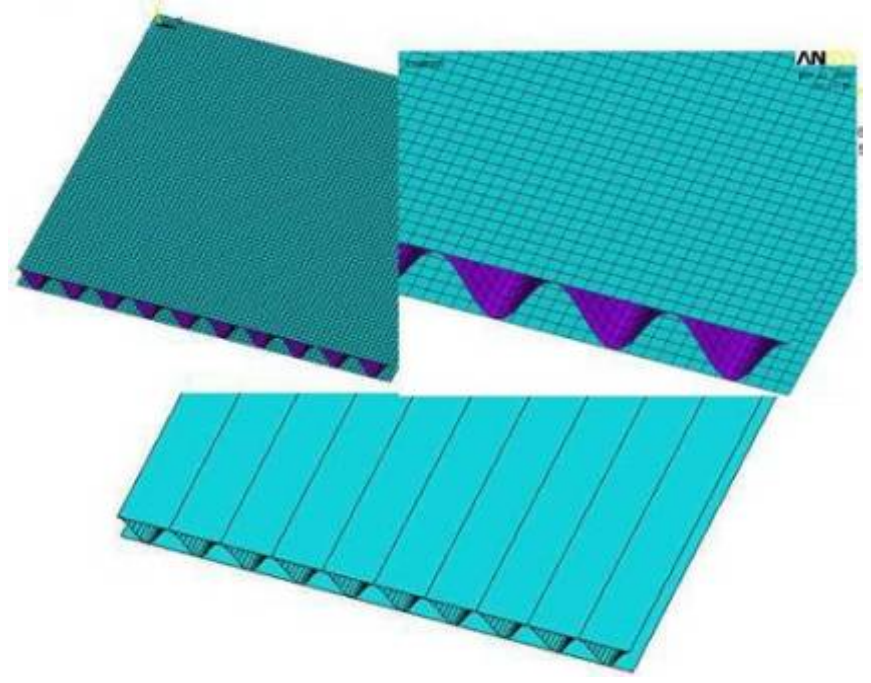

Fig. (3). Model and mesh of corrugated fiberboard

The method of determining the element size to create mesh can be employed in this study. The model and mesh of corrugated fiberboard are shown in Fig. (3).

Confirm the boundary conditions. To obtain an effective scheme for the layout pattern of the corrugated fiberboard, attention should be given to the boundary conditions. The boundary conditions of the FEM structure determine the DOF (degree of freedom) of the structure and loading.

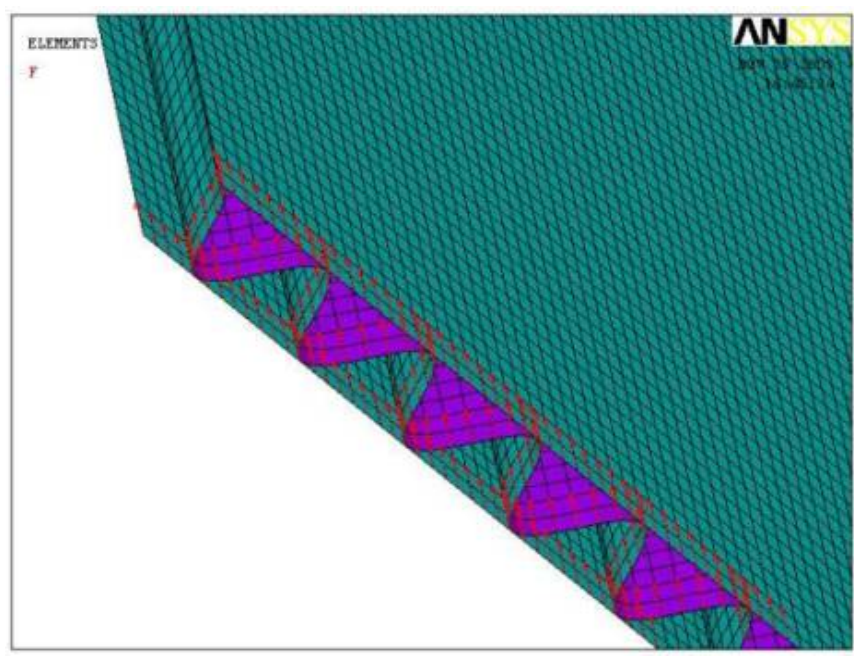

Fig. (4). Load of single-wall corrugated fiberboard.

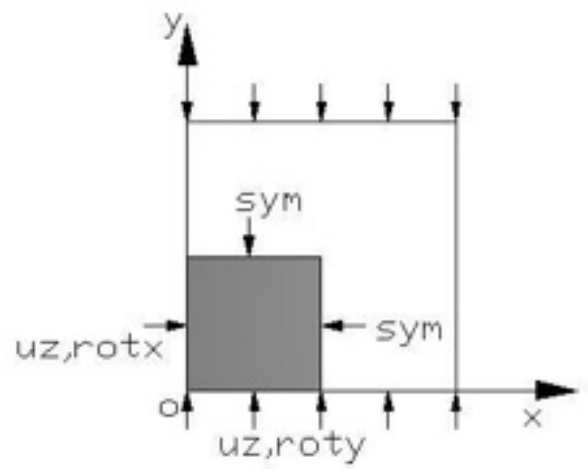

Fig. (5). Boundary conditions of corrugated fiberboard. 
A unit load is applied to the single-wall corrugated fiberboard, with the process of loading as shown in Fig. (4). The corrugated pressure can be applied on the nodes along the direction of the fiberboard, in which the force of overall nodes can be set to $1 \mathrm{~N}$. According to the principle of compression strength, simple-support constraint is applied on the corrugated fiberbooard, as shown in Fig. (5). Combining this with the method of FEM analysis, in which the two sides of the constraints are imposed symmetrically, the rest of the edges of corrugated can be restricted by moving perpendicular to paper and whirling around the axis of the plane.

\section{THE EIGENVALUE BUCKLING ANALYSIS OF CORRUGATED FIBERBOARD}

Eigenvalue buckling analysis is usually carried out to determine the upper limit of the buckling load for a structure. Nonlinear buckling analysis aims to study the relation between load and deformation of a structure. The load for nonlinear buckling analysis of a structure may be limited by the load obtained from eigenvalue buckling analysis. The eigenvalue buckling analysis is utilized to forecast a theoretical buckling load of an ideal elastic structure.

In order to solve the eigenvalue problem, the balance equation of corrugated fiberboard should be developed initially as follow:

$\left\{P_{0}\right\}=\left[\left[K_{e}\right]+\left[K_{\sigma}\right]\right]\left\{u_{0}\right\}$

Where $\left\{u_{0}\right\}$ is the displacement for applying load $\left\{P_{0}\right\}$, $\left[K_{e}\right]$ is the stiffness matrix which is

$$
\left[K_{e}\right]=\int[B]^{T}[C][B] d \bar{V}=\int[B]^{T}[C][B] d \xi d \eta d \xi
$$

$B$ is an interpolation matrix obtained by imposing the considered set of shape functions.

Transferring to bulking equation of corrugated fiberboard

$\{P\}=\left[\left[K_{e}\right]+\lambda\left[K_{\sigma}\right]\right]\{u\}$

$\{p\}$ an $\mathrm{d}\left\{p_{0}\right\},\{u\}$ and $\left\{u_{0}\right\}$ are linear

relationships respectively, that is

$\{p\}=\lambda\left\{p_{0}\right\} \quad\{u\}=\lambda\left\{u_{0}\right\}$

When $\lambda$ reaches a value

$\left[\left[k_{e}\right]+\lambda\left[k_{\sigma}\right]\right]\{u\}=0$

And then

$$
\operatorname{det}\left[\left[k_{e}\right]+\lambda\left[k_{\sigma}\right]\right]=0
$$

According to the eigenvalue theory, the results show that the corrugated fiberboard had already buckled. Therefore, the critical buckling load, $F_{c r}$, and critical buckling pressure, $P_{c r}$, could now be obtained by using an eigenvalue equation.
$\left\{F_{c r}\right\}=\lambda\left\{F_{0}\right\} \quad\left\{P_{c r}\right\}=\lambda\left\{P_{0}\right\}$

ANSYS was used to conduct the eigenvalue buckling analysis of corrugated fiberboard. With values of height $h=8.0 \mathrm{~mm}$, and $\lambda=4.5 \mathrm{~mm}$, the model was constructed (length of side $\times 10$ wavelength). The results showed that the eigenvalue is the value of buckling load. FACT $=1413$ (shown in Fig. 6) represents the eigenvalue obtained by eigenvalue buckling analysis, which is regarded as the load value in nonlinear buckling analysis.

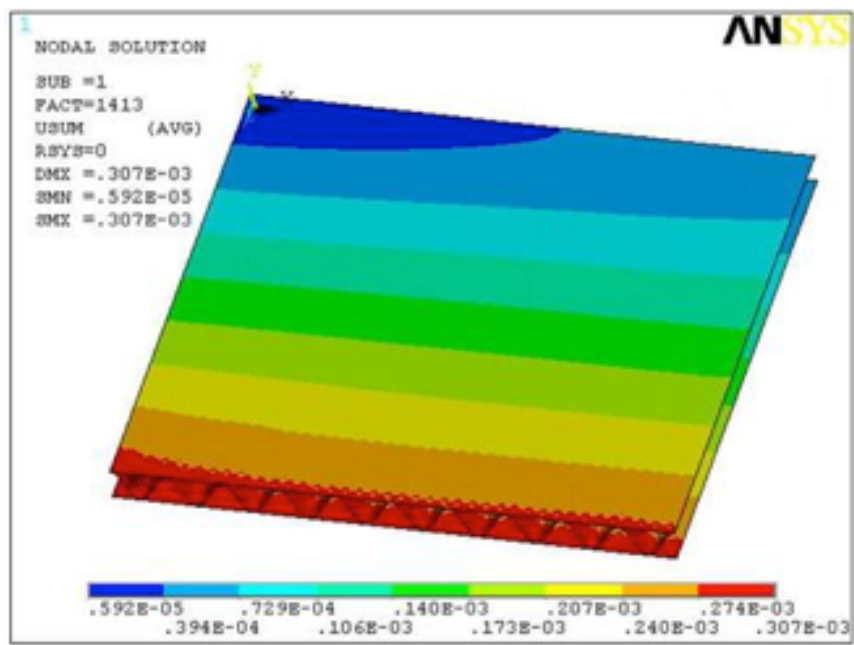

Fig. (6). Analysis results at $8.0 \mathrm{~mm}$ wavelength $4.5 \mathrm{~mm}$ height.

During the analysis, the buckling deformation of shape was obtained with the expansion of buckling mode. As shown in Fig. (7), both the first mode and the second mode of the single-wall corrugated fiberboard were analyzed for the buckling mode of $1413 \mathrm{~N}$ and $1586 \mathrm{~N}$, respectively. Regarding the linear buckling mode as the initial geometrical defect of the structure, the nonlinear analysis of composite case under the applied load was constructed by means of the finite element method.

\section{THE NONLINEAR BUCKLING ANALYSIS OF CORRUGATED FIBERBOARD}

For the sake of deriving the bucking load, the method of equilibrium iteration can be employed based on nonlinear buckling analysis of corrugated fiberboard. In particular, if deformation increases rapidly, or if deformation increases with a decreasing load, this would be a buckled state, and the corresponding load would be regarded as the bucking load.

The New-Raphson (NR) method and the Arc-length method can be applied in solving the process. If only the NR method is applied for the process of solving, the tangential stiffness matrix may overlap with the reduced order matrix which leads to the serious problem of convergence. In this case, the Arc-length method can be used for accurate solution. The Arc-length method is used to converge NR equilibrium iteration. Thus, even if the slope of the tangential stiffness matrix is zero or negative, it often prevents divergence in the final solution.

An initial defect or minor disturbance should be exerted on nonlinear buckling analysis in order to create a nonlinear structure so that the above result (of eigenvalue 

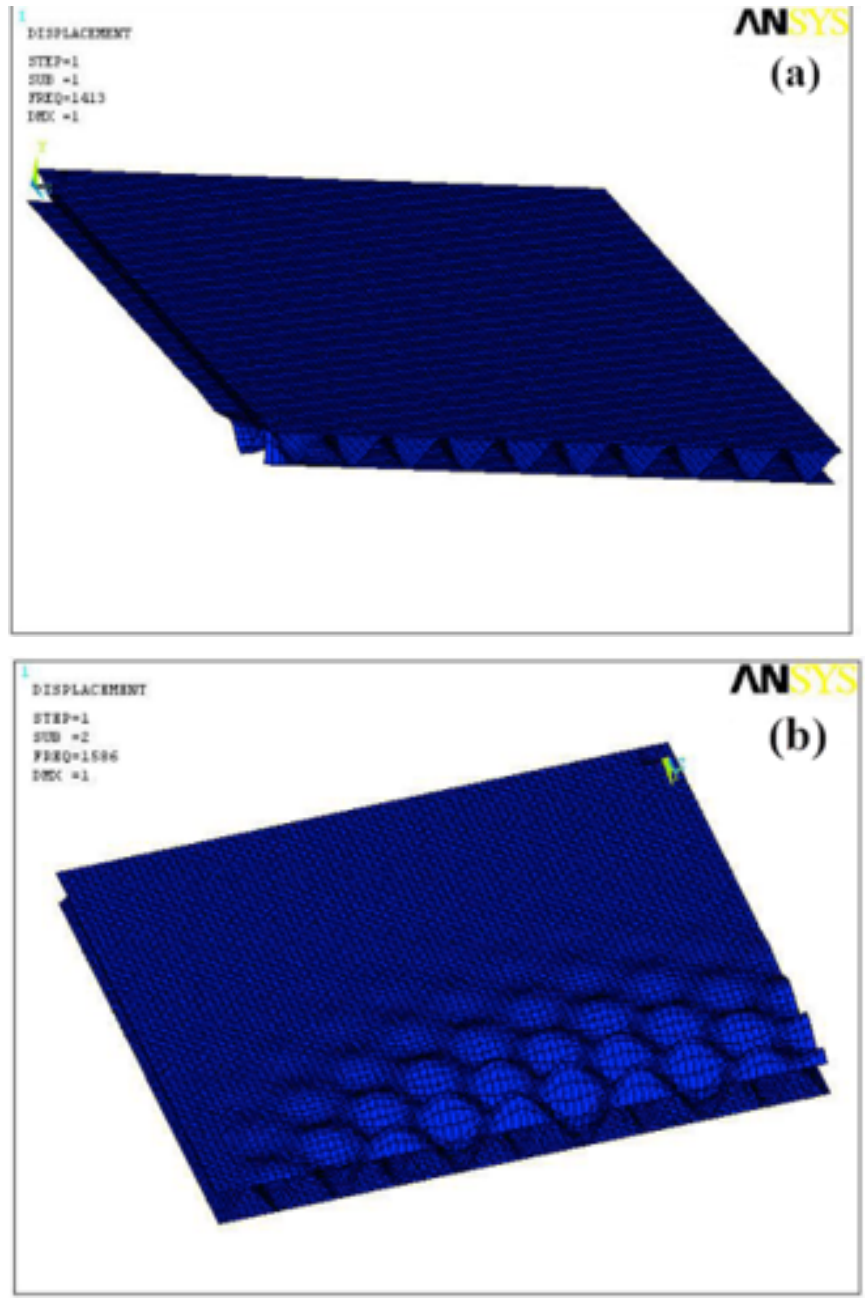

Fig. (7). First-order and Second-order deflection of eigenvalue buckling analysis ((a) first-order deformation (b) second-order deformation).

buckling analysis of corrugated fiberboard) could be utilized. Corrugated fiberboard containing a small amount of deformation ( $5 \%$ of deformation under the eigenvalue buckling load) was chosen in this paper. It was analyzed under an essential load (choose $1600 \mathrm{~N}$ load in this paper) that was greater than the eigenvalue buckling load $(1413 \mathrm{~N})$ by $10 \% \sim 20 \%$.

Table 2. Load at each time step.

\begin{tabular}{|c|c|c|c|c|}
\hline Time step & 1.699 & 1.719 & 1.739 & 1.759 \\
\hline Load(N) & 1118.4 & 1150.2 & 1182.7 & 1213.8 \\
\hline
\end{tabular}

Table 2 shows the results at each step of FEM. Specifically, the description of the entire deformation process from steps 1.699 to 1.759 is shown in Figs. $(\mathbf{8}, \mathbf{9})$. When the load was increased from $1150.2 \mathrm{~N}$ to $1182.7 \mathrm{~N}$, the corrugated fiberboard could be considered buckled, with obvious deformation fluctuation. Therefore, the ultimate buckling load should be regarded as $1150.2 \mathrm{~N}$.

\section{THE MECHANICAL PROPERTIES ANALYSIS OF CORRUGATED FIBERBOARD}

With the above analysis, the result of eigenvalue buckling analysis was obtained and conveniently compared.
The results, as shown in Table $\mathbf{3}$, describe the length of square of corrugated fiberboard as ten times the wavelength, with wavelength declining within the range of 8.0 and $9.5 \mathrm{~mm}$, and the height declining within the range of 4.5 and $5.5 \mathrm{~mm}$. As can be noted from Table 3 the buckling load increased as the height increased while length and width were kept constant. On the other hand, variation in buckling load was not independent of wavelength. This suggested that buckling load is also associated with the wavelength of the material. Therefore, the following results concluded that the mechanical performance of corrugated fiberboard can be improved by increasing the height of corrugated fiberboard and decreasing wavelength.

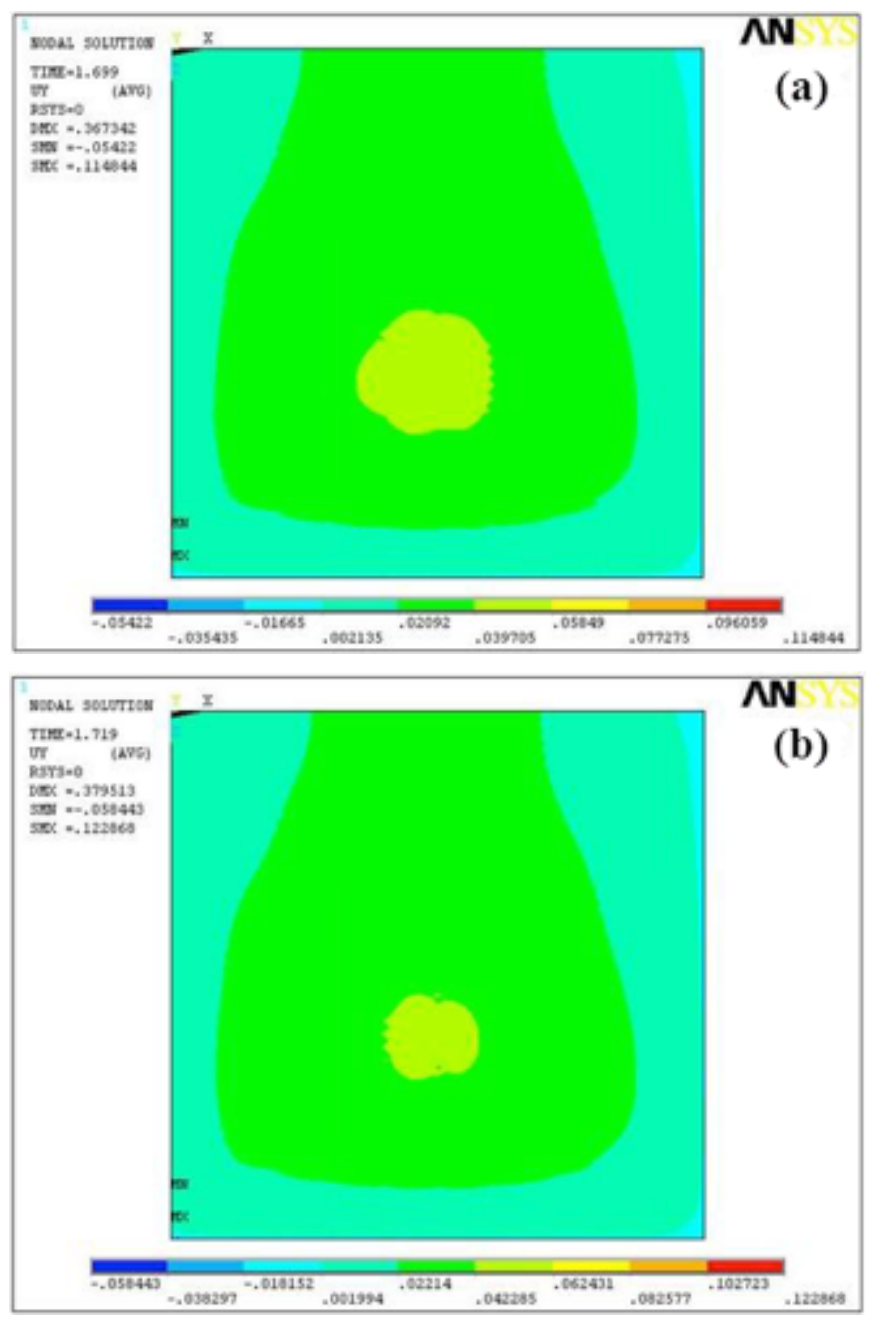

Fig. (8). Deformation map perpendicular to corrugated fiberboard's panel at time step 1.699 and 1.719 ((a) with the time step 1.699 (b) with the time step 1.719).

In order to investigate the mechanical properties of fourlayer and five-layer corrugated fiberboard, a finite element 3$\mathrm{D}$ model was established by APDL, utilizing the same conditions and materials (meshing elements to single-wall fiberboard). The following results of eigenvalue buckling analysis and static analysis were discussed with the variation of modification parameters $\lambda$ and $h$, brought about by applying two sheets loads and a tiny displacement $S$ to one layer together with another layer for all constraints. 

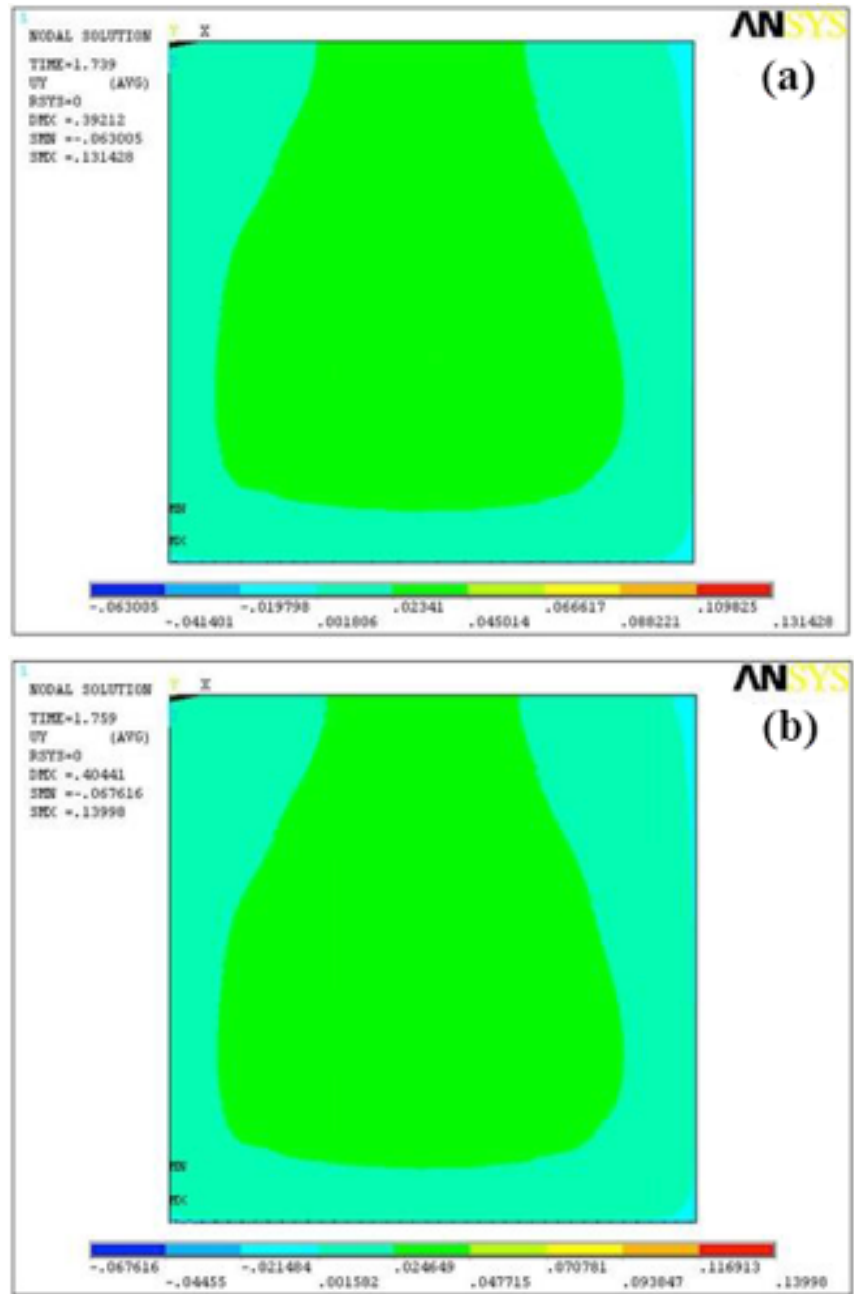

Fig. (9). Deformation map perpendicular to corrugated fiberboard's panel at time step 1.739 and 1.759 ((a) with the time step 1.739 (b) with the time step 1.759).

Table 3. Results of eigenvalue buckling analysis.

\begin{tabular}{|c|c|c|c|c|c|c|}
\hline & $\mathbf{4 . 5}$ & $\mathbf{4 . 6}$ & $\mathbf{4 . 7}$ & $\mathbf{4 . 8}$ & $\mathbf{4 . 9}$ & $\mathbf{5 . 0}$ \\
\hline \hline 8.0 & 1413 & 1520 & 1523 & 1526 & 1529 & 1531 \\
\hline 8.3 & 1365 & 1368 & 1370 & 1373 & 1375 & 1377 \\
\hline 8.6 & 1336 & 1338 & 1340 & 1343 & 1345 & 1347 \\
\hline 8.9 & 1307 & 1309 & 1311 & 1314 & 1313 & 1318 \\
\hline 9.2 & 1329 & 1332 & 1334 & 1337 & 1339 & 1342 \\
\hline 9.5 & 1300 & 1303 & 1305 & 1308 & 1310 & 1380 \\
\hline
\end{tabular}

The results of eigenvalue buckling analysis for four-layer and five-layer corrugated fiberboard are shown in Table 4. According to comparison, by analyzing the effect of $\lambda$ and $h$, it was observed that the eigenvalue gradually increased by increasing the size of $h$. However, the opposite results are shown in Table 4, which show that with increase in the size of $\lambda$, eigenvalue decreased regardless of four-layer and fivelayer fiberboard. Therefore, the $\lambda$ and $h$ should be taken into account in the research of mechanical behaviors of fiberboard. In addition, as illustrated in Table 4, the eigenvalue of five-layer corrugated board was 3179 and the eigenvalue of the four-layer was 2439 at $\lambda=8.0 \mathrm{~mm}$ and $h=4.5 \mathrm{~mm}$, indicating the preferably cushioning behaviors of five-layer board with similar height and wavelength.

Table 4. Results of eigenvalue for four-layer and five-layer corrugated fiberboard.

\begin{tabular}{|c|c|c|}
\hline & $\begin{array}{l}\text { Four-Layer } \\
\text { Corrugated } \\
\text { Fiberboard }\end{array}$ & $\begin{array}{l}\text { Five-Layer } \\
\text { Corrugated } \\
\text { Fiberboard }\end{array}$ \\
\hline \hline$\lambda=8.0, h=4.5$ & 2439 & 3179 \\
\hline$\lambda=8.0, h=4.7$ & 2491 & 3543 \\
\hline$\lambda=8.5 h=4.5$ & 2273 & 3102 \\
\hline
\end{tabular}

(a) four-layer corrugated fiberboard

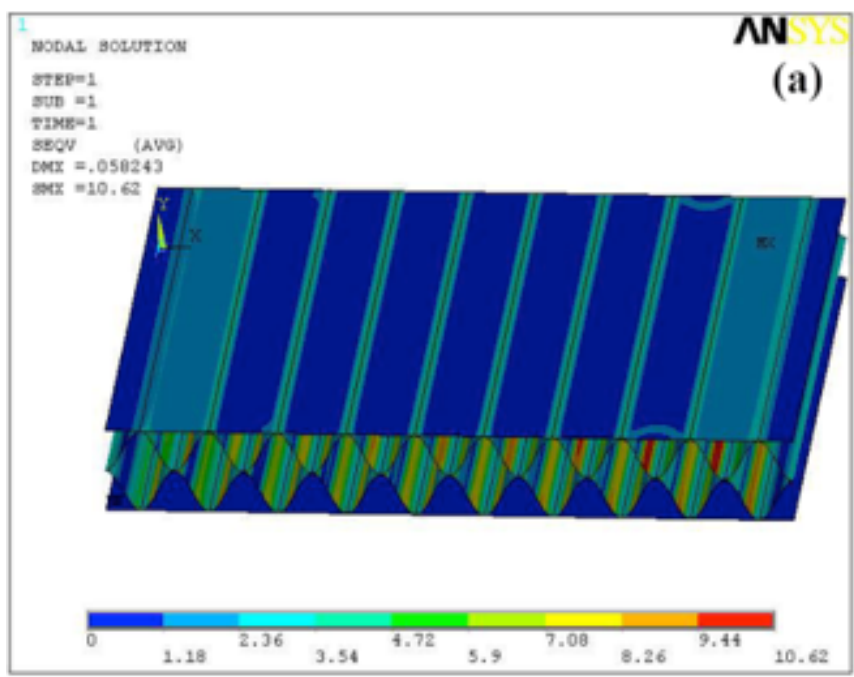

(b) five-layer corrugated fiberboard

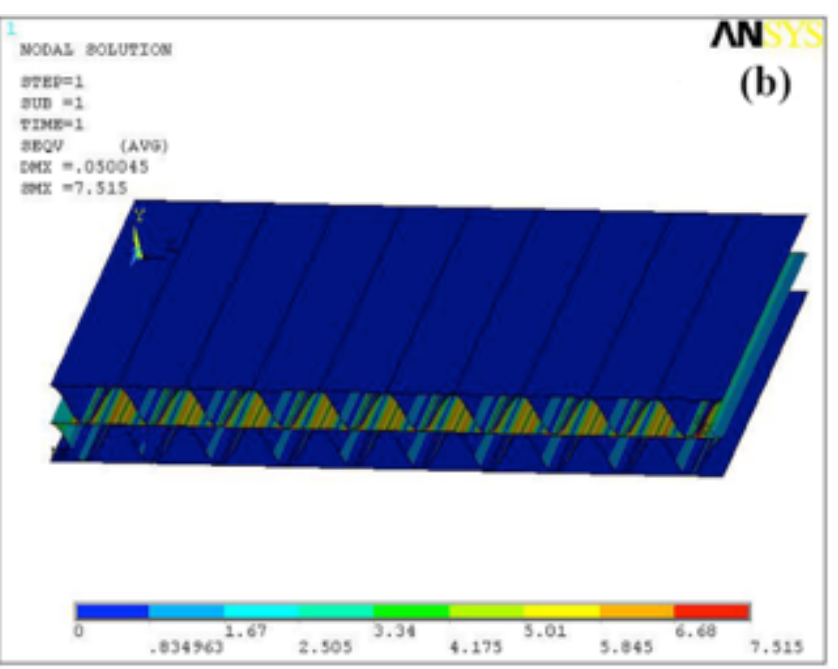

Fig. (10). Comparison of static analysis for four-layer and fivelayer corrugated fiberboard at $\mathrm{S}=0.05 \mathrm{~mm}$.

The results of static analysis for four-layer and five-layer corrugated fiberboard are given in Figs. (10, 11) and Fig. (12). It is apparent that the distinct maximum stress can be 
(a) four-layer corrugated fiberboard

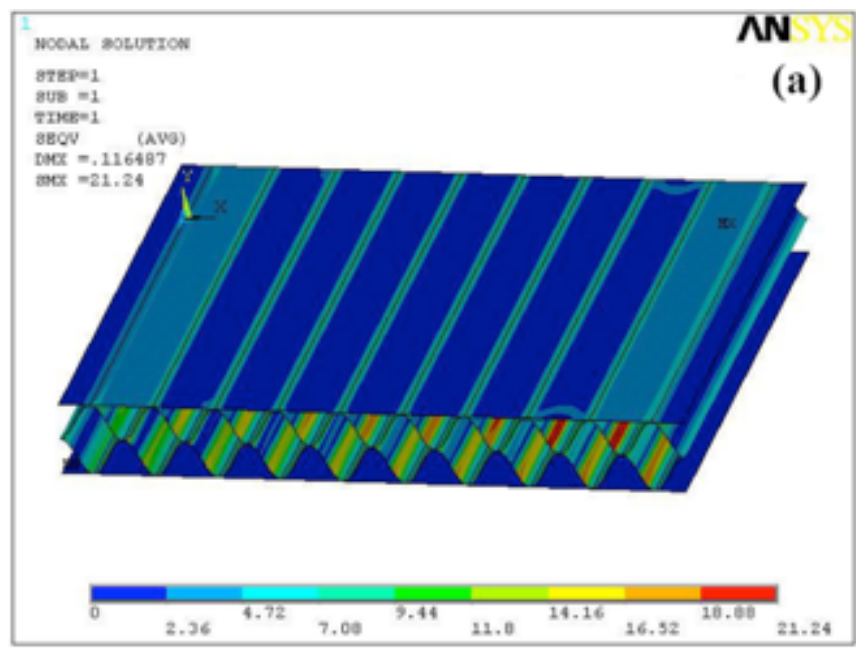

(b) five-layer corrugated fiberboard

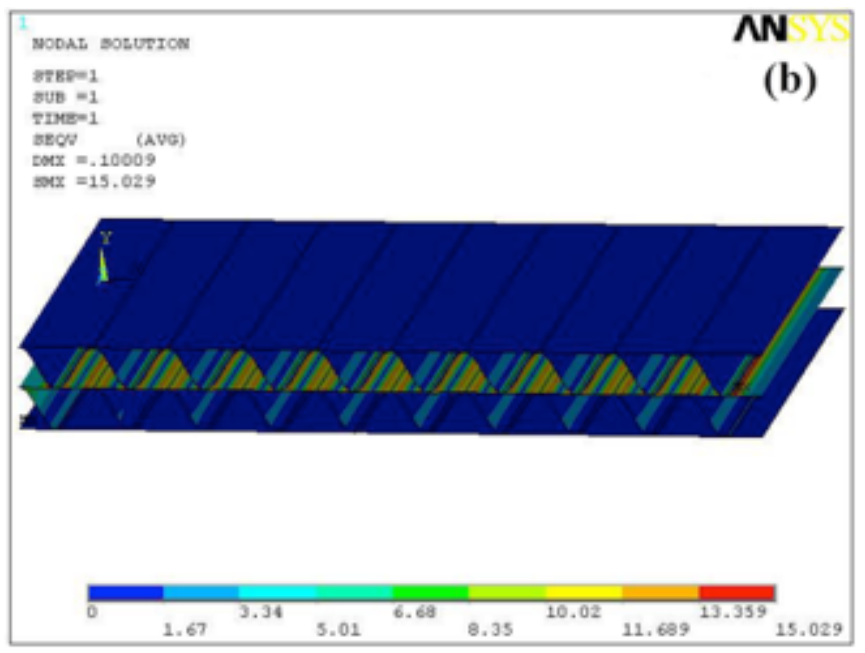

Fig. (11). Comparison of static analysis for four-layer and fivelayer corrugated fiberboard at $\mathrm{S}=0.1 \mathrm{~mm}$.

achieved by changing the parameter of $S$, applying separately for the four-layer and five-layer fiberboard. In accordance with these results, the maximum stress can be higher with the increased dimension of $S$. Furthermore, as illustrated in Fig. (10), the maximum stress of five-layer corrugated board was observed to be $10.62 \mathrm{Mpa}$ and of the four-layer it was $7.515 \mathrm{Mpa}$ while the $S$ was observed to be $0.05 \mathrm{~mm}$. From this, it can be concluded that the maximum stress of four-layer corrugated fiberboard was about 70 percent for five-layer corrugated board. Similar results were observed as shown in Fig. (11) as well as in Fig. (12), indicating superior stiffness of four-layer corrugated fiberboard and increasing utilization rate of raw materials.

\section{CONCLUSION}

This paper attempts to provide a study on corrugated fiberboard buckling analysis based on FEM. The comparatively ideal buckling load can be obtained by exerting simple support constraints on corrugated fiberboard. Eigenvalue buckling analysis can efficiently forecast the buckling load of corrugated fiberboard, therefore, can be used as the upper limit for nonlinear buckling analysis. Furthermore, the load deformation of corrugated fiberboard can well confirm the buckling load comparatively. Based on this research, through nonlinear buckling analysis, the buckling load was observed to be $81.4 \%$ of the eigenvalue. In addition, the mechanical performance of corrugated fiberboard can be greatly affected by the height and wavelength of corrugated fiberboard.

(a) four-layer corrugated fiberboard

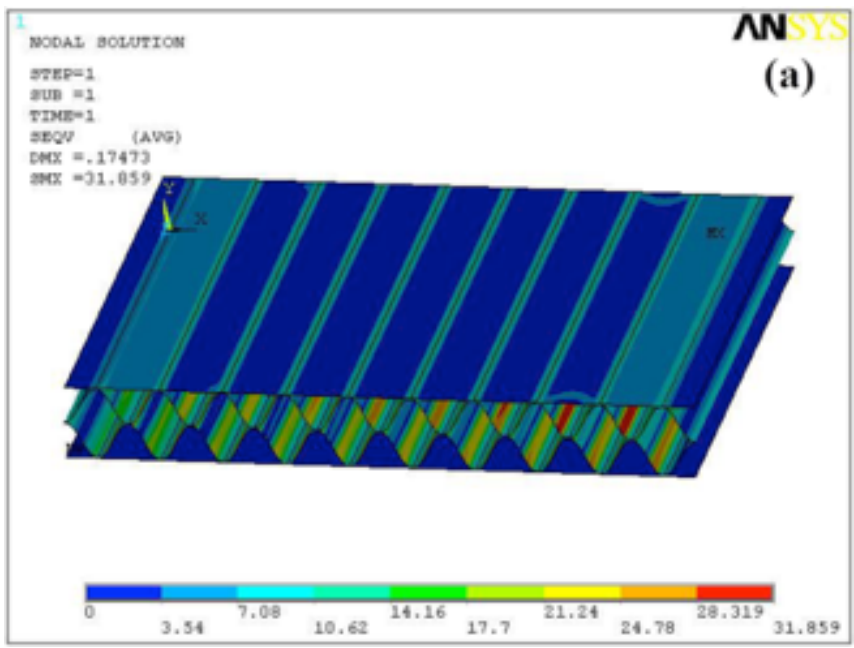

(b) five-layer corrugated fiberboard

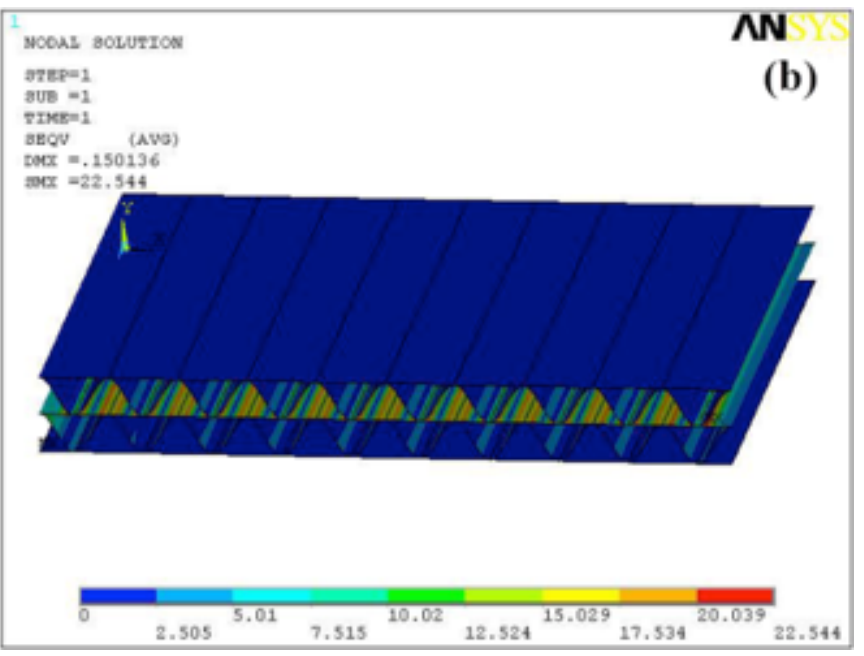

Fig. (12). Comparison of static analysis for four-layer and fivelayer corrugated fiberboard at $S=0.15 \mathrm{~mm}$.

According to the eigenvalue buckling analysis and static analysis, the results indicated that buckling load between the four-layer and five-layer corrugated fiberboard varied greatly. The maximum stress of five-layer corrugated fiberboard was about 70 percent of four-layer board under the conditions of the same compression deformation, showing superior stiffness of four-layer corrugated fiberboard and preferably cushioning behaviors of five-layer board. The results of buckling analysis were finally elaborated to demonstrate the effectiveness and accuracy of the proposed method.

\section{CONFLICT OF INTEREST}

The authors confirm that this article content has no conflict of interest. 


\section{ACKNOWLEDGEMENTS}

Declared none.

\section{REFERENCES}

[1] M.W. Jr Johnson, and T.J. Urbanik, "Analysis of the localized buckling in composite plate structures with application to determining the strength of corrugated fiberboard", J. Compos. Technol. Res., vol. 11, pp. 121-128, 1989.

[2] U. Nyman, and P.J. Gustafsson, "Material and structural failure criterion of corrugated board facings", Compos. Struct., vol. 50, pp. 79-83, 2000

[3] T.T. Lu, C. Chen, and G. Zhu, "Compressive behavior of corrugated board panels", Compos. Mater., vol. 35, pp. 2098-2126, 2001.
[4] M. E. Biancolini, and C. Brutti, "Numerical and experimental investigation of the strength of corrugated board packages", Packaging Technol. Sci., vol. 16, pp. 47-60, 2003.

[5] N. Buannic, P. Cartraud, and T. Quesnel, "Homogenization of corrugated core sandwich panels", Compos. Struct., vol. 59, pp. 299-312, 2003.

[6] R. Haj-Ali, C. Joonho, and W. Bo-Siou, "Refined nonlinear finite element models for corrugated fiberboards", Compos. Struct., vol. 87, pp. 321-333, 2009.

[7] J. Zhang, P. Supernak, S. Mueller-Alander, and C.H. Wan, "Improving the bending strength and energy absorption of corrugated sandwich composite structure", Mater. Des., vol. 52, pp. 767-773, 2013

(C) Ma et al.; Licensee Bentham Open

This is an open access article licensed under the terms of the Creative Commons Attribution Non-Commercial License (http://creativecommons.org/licenses/by-nc/4.0/) which permits unrestricted, non-commercial use, distribution and reproduction in any medium, provided the work is properly cited. 